\title{
AVALIAÇÃO DE SISTEMAS DE TERRAS
}

\section{Aspetos gerais}

Conseguir o valor ótimo de terra é fundamental para a segurança e eficiência de uma instalação elétrica.

Muitos profissionais têm dificuldade em determinar o método ideal e por vezes recorrem às tentativas, conseguindo na maioria dos casos o valor desejado espontaneamente sem perceber muito bem como o encontrou.

Será importante compreender a influencia do solo, os vátios métodos para conseguir uma boa terra e como decidir quanto á profundidade dos elétrodos. Poderemos tendo em consideração o que se vai expor de seguida decidir baseado em técnicas comprovadas, determinar valores de terras com algum conhecimento prévio através de medidas e análise de dados.

Qual a finalidade dos sistemas de terra?

- Ligações à terra por razões de proteção (544 RTIEBT)

- Ligações à terra por razões funcionais (545 RTIEBT)

- Ligações à terra por razões combinadas de proteção e funcionais (546 RTIEBT)

- Condutores de equipotencialidade (547 RTIEBT)

As suas principais aplicações são:

- Terra de serviço nos PT's

- Terra de proteção

- Retorno em sistemas CC

- Sistemas de comunicação

- Na descarga eletrostática

- Para raios

- Filtragem de interferências eletromagnéticas

\section{Ligações à terra}

Segundo as regras técnicas no ponto 542.1.2 RTIEBT, diz o seguinte:

A seleção e a instalação dos equipamentos que garantem a ligação à terra devem ser tais que:

a) O valor de resistência dessa ligação esteja de acordo com as regras de proteção e de funcionamento da instalação e que permaneça dessa forma ao longo do tempo;

b) As correntes de defeito à terra e as correntes de fuga possam circular, sem perigo, nomeadamente no que respeita às solicitações térmicas, termomecânicas $e$ eletromecânicas;

c) A solidez e a proteção mecânica sejam garantidas em função das condições previstas de influências externas

\section{Elétrodos de terra}

Podem ser usados como elétrodos de terra (RTIEBT 542.2) os elementos metálicos seguintes:

- Tubos, varetas ou perfilados;

- Fitas, varões ou cabos nus;

- Chapas;

- Anéis (de fitas ou de cabos nus) colocados nas fundações dos edifícios;

- Armaduras do betão imerso no solo;

- Canalizações (metálicas) de água, desde que satisfaçam ao indicado na secção 542.2.5 RTIEBT;

- Outras estruturas enterradas apropriadas.

De um modo geral, a melhor solução para os elétrodos de terra, consiste na utilização de anéis colocados na base das fundações dos edifícios, durante a construção, tendo como principais vantagens: 
a) Utilizarem trabalhos de aterro previstos pela construção;

b) Estão a uma profundidade que, permite salvaguardar, situações resultantes das variações climáticas;

c) Garantem um bom contacto com o solo;

d) Reduzem, ao mínimo, o valor da resistência de terra;

e) Poderem ser usados desde o início da construção como elétrodo de terra para proteção no estaleiro.

O anel referido anteriormente pode ser constituído por:

- 1 Cabo de cobre nu de $25 \mathrm{~mm}^{2}$ de secção mínima;

- 1 Fita de aço galvanizado de $100 \mathrm{~mm}^{2}$ de secção mínima e $3 \mathrm{~mm}$ de espessura mínima ou um cabo de aço galvanizado de $100 \mathrm{~mm}^{2}$ de secção mínima, embebido no próprio betão das fundações.

Quando recorremos a um elétrodo de terra, chapas, ou varetas, os tubos e os perfilados devem, normalmente ficar enterrados verticalmente no solo, a uma profundidade não inferior a $0,80 \mathrm{~m}$.

As seções mínimas convencionais dos condutores de terra devem obedecer segundo as RTIEBT ao estabelecido na tabela 1.

\begin{tabular}{|c|c|c|}
\hline $\begin{array}{c}\text { Condutor de } \\
\text { terra }\end{array}$ & $\begin{array}{c}\text { Protegido } \\
\text { mecanicamente }\end{array}$ & $\begin{array}{r}\text { Não protegido } \\
\text { mecanicamente }\end{array}$ \\
\hline $\begin{array}{c}\text { Protegido } \\
\text { contra a } \\
\text { corrosão }\end{array}$ & $\begin{array}{c}\text { De acordo com a } \\
\text { secção } 543.1\end{array}$ & $\begin{array}{c}16 \mathrm{~mm}^{2} \text {, se de cobre nu } \\
\text { ou de aço galvanizado }\end{array}$ \\
\hline $\begin{array}{c}\text { Não protegido } \\
\text { contra a } \\
\text { corrosão }\end{array}$ & $25 \mathrm{~mm}^{2}$, se de cobre \\
\hline
\end{tabular}

Tabela 1. Seções mínimas convencionais dos condutores de terra (RTIEBT)
Na sequência do referido na secção 543.1.1 RTIEBT, a secção dos condutores de proteção não deve ser inferior à que resulta da aplicação da expressão seguinte (válida apenas para $\mathrm{t} \leq 5 \mathrm{~s})$ :

$$
\mathrm{S}=\frac{\mathrm{I} \sqrt{\mathrm{t}}}{\mathrm{k}}
$$

Onde:

S - secção do condutor de proteção, em milímetros quadrados;

I - valor eficaz da corrente de defeito que pode percorrer o dispositivo de proteção

$\mathrm{t}$ - tempo de funcionamento do dispositivo de corte, em segundos;

k - fator cujo valor depende da natureza do metal do condutor de proteção, do , (veja-se o anexo VI RTIEBT, referido na tabela 2 )

\begin{tabular}{|c|c|c|c|}
\hline & \multicolumn{3}{|c|}{$\begin{array}{c}\text { Natureza do isolamento dos } \\
\text { condutores de proteção ou } \\
\text { da bainha exterior dos cabos }\end{array}$} \\
\hline & PVC & $\begin{array}{c}\text { XLPE } \\
\text { ou } \\
\text { (EPR) }\end{array}$ & $\begin{array}{r}\text { Borracha } \\
\text { butílica }\end{array}$ \\
\hline Temperatura final $\left({ }^{\circ} \mathrm{C}\right) \Rightarrow$ & 160 & 250 & 220 \\
\hline Material do condutor $\Downarrow$ & & Valores de k \\
\hline Cobre & 143 & 176 & 166 \\
\hline Alumínio & 95 & 116 & 110 \\
\hline Aço & 52 & 64 & 60 \\
\hline
\end{tabular}

Nota: A temperatura inicial do condutor foi considerada igual a $30^{\circ} \mathrm{C}$

Tabela 2. Valores de $\mathrm{k}$ para condutores de proteção isolados e não incorporados em cabos e para condutores de proteção nus em contacto com a bainha exterior dos cabos

No quadro 54F das RTIEBT os valores referidos só são válidos para condutores de proteção do mesmo metal que os condutores ativos. 
Tabela 3. Secções mínimas dos condutores de proteção

(Quadro 54F-RTIEBT)

\begin{tabular}{|c|c|}
$\begin{array}{c}\text { Secção dos condutores } \\
\text { de fase da instalação } \\
\text { SF }\left(\mathrm{mm}^{2}\right)\end{array}$ & $\begin{array}{c}\text { Secção mínima dos } \\
\text { condutores de proteção } \\
\text { SPE }\left(\mathrm{mm}^{2}\right)\end{array}$ \\
\hline SF 16 & SPE $=$ SF \\
\hline 16 SF 35 & SPE $=16$ \\
\hline SF 35 & SPE $=$ SF $/ 2$ \\
\hline
\end{tabular}

No ponto 547.1.1 RTIEBT refere secções mínimas do condutor de equipotencialidade principal que deve ter uma secção não inferior a metade da secção do condutor de proteção de maior secção existente na instalação, com o mínimo de $6 \mathrm{~mm}^{2}$, podendo, contudo esse valor ser limitado a $25 \mathrm{~mm}^{2}$, se de cobre, ou a uma secção equivalente, se de outro metal.

Todas as instalações elétricas devem ter um terminal principal de terra (542.4.1 RTIEBT), ao qual devem ser ligados:

- Condutores de terra;

- Condutores de proteção;

- Condutores das ligações equipotenciais principais;

- Condutores de ligação à terra funcional, se necessário.

Nos condutores de terra, deve ser previsto um dispositivo instalado em local acessível e que permita a medição do valor da resistência do elétrodo de terra das massas, podendo esse dispositivo estar associado ao terminal principal de terra. Este dispositivo deve ser, apenas, desmontável por meio de ferramenta e deve ser mecanicamente seguro e garantir a continuidade elétrica das ligações à terra (542.4.2 RTIEBT).

O valor da resistência da terra depende fundamentalmente:

- A resistência de contacto entre o equipamento protegido e do condutor de terra.

- A impedância do condutor e contacto da conexão dos elétrodos.

- A resistência do próprio elétrodo.

- A resistência de contato entre o elétrodo solo.

- A resistência do sistema de elétrodos.

Para obter uma boa terra devemos atender aos seguintes fatores:

- Tipo de terreno,

- Humidade do terreno,

- $\quad$ Salinidade do solo,

- Temperatura terreno,

- Granulação do terreno,

- $\quad$ Compactação do terreno,

- Estratografia,

- E outros.

Valores médios da resistividade de alguns tipos de terreno são indicados na tabela 4.

Tabela 4. Resistividade dos terrenos de acordo com a sua natureza

\begin{tabular}{|l|c|l|c|}
\hline \multicolumn{1}{|c|}{ Natureza do terreno } & $\begin{array}{c}\text { Resistividade } \rho \\
\Omega \cdot m\end{array}$ & \multicolumn{1}{|c|}{ Natureza do terreno } & \multicolumn{2}{c|}{$\boldsymbol{\Omega} \cdot \mathbf{m}$} \\
\hline Terreno pantanoso & 1 a 30 & Mármore argila compacta & 100 a 200 \\
\hline Turfa húmida & 5 a 100 & Calcários maciços & 100 a 300 \\
\hline Húmus & 10 a 50 & Granito muito alterado & 100 a 600 \\
\hline Lama & 20 a 100 & Areia siliciosa & 200 a 3000 \\
\hline Mármores jurássicos & 30 a 40 & Solo pedregoso (relva) & 300 a 500 \\
\hline Argila plástica & 50 & Calcários fissurados & 500 a 1000 \\
\hline Areia argilosa & 50 a 500 & Calcários compactos & 1000 a 5000 \\
\hline Xistos & 50 a 300 & Solo pedregoso & 1500 a 3000 \\
\hline
\end{tabular}




\section{Sistemas de Terra (fonte RTIEBT edição anotada)}

Existe a terra de serviço, onde habitualmente é ligado o neutro nos postos de transformação (PT) aqui também designada por terra de alimentação e a terra de proteção, designada por terra das massas onde deve ser ligado o elétrodo de terra correspondente.

Uma boa terra não deverá exceder os 20 Ohm e deverá sempre ser verificada anualmente no estio recorrendo ao método de dois elétrodos auxiliares que vêm a equipar os mega ohmímetros destinados para o efeito.

Há várias configurações de ligação à terra do neutro e do condutor de terra de proteção estando estes esquemas das ligações à terra, nas RTIEBT, indicados nas secções 312.2.1 a 312.2.4. RTIEBT

\section{- $\quad$ Regime TT}

O esquema TT tem um ponto da alimentação ligado à terra, sendo as massas da instalação elétrica ligadas a elétrodos de terra distintos do elétrodo de terra da alimentação.
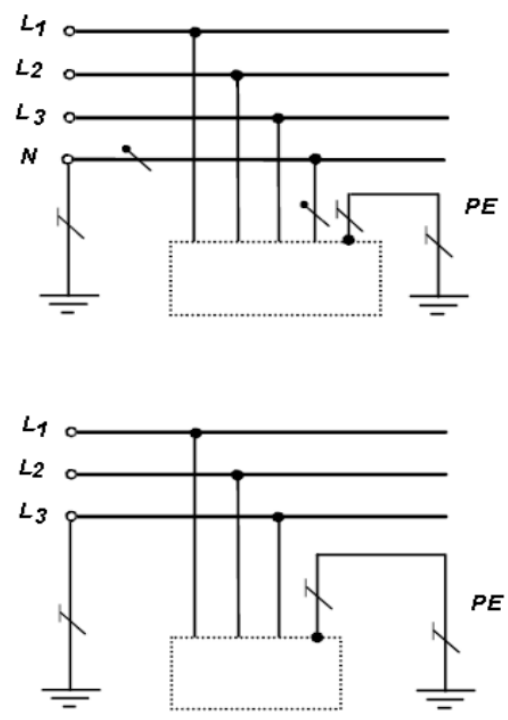

Figura 1 . Esquema TT (RTIEBT edição anotada)

\section{- $\quad$ Regime TN}

- $\quad \mathrm{TN}-\mathrm{C}$

As funções de neutro e de proteção são combinadas num único condutor (PEN) em todo o circuito.

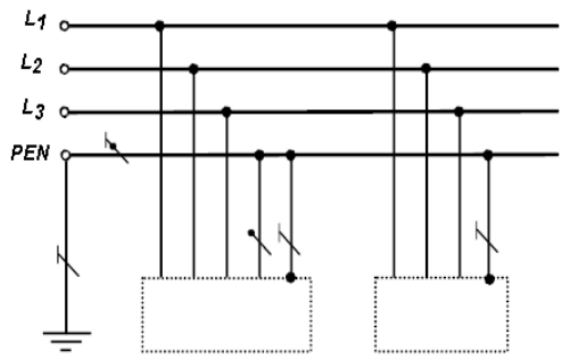

Figura 2. Esquema TN-C (RTIEBT edição anotada)

- TN - S

As funções de neutro e de proteção são combinadas num único condutor (PEN) em todo o circuito.

Condutor neutro e de proteção separados em todo o esquema.

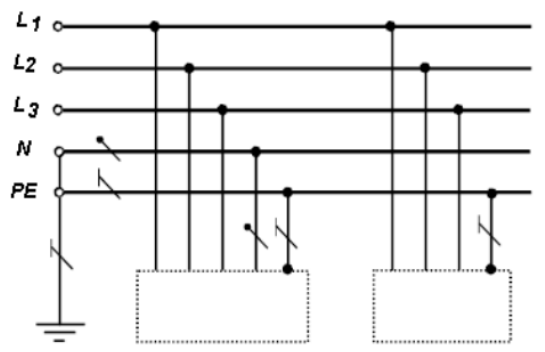

Figura 3. Esquema TN-S (RTIEBT edição anotada)

Condutor ativo ligado à terra e condutor de proteção separado em todo o circuito.

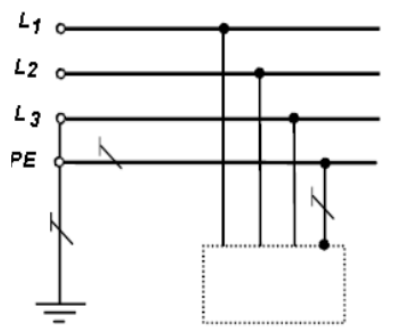

Figura 3a. Esquema TN-S (RTIEBT edição anotada) 


\section{ARTigo Técnico}

- $\quad \mathrm{TN}-\mathrm{C}-\mathrm{S}$

As funções de neutro e de proteção são combinadas num único condutor (PEN) numa parte do circuito.

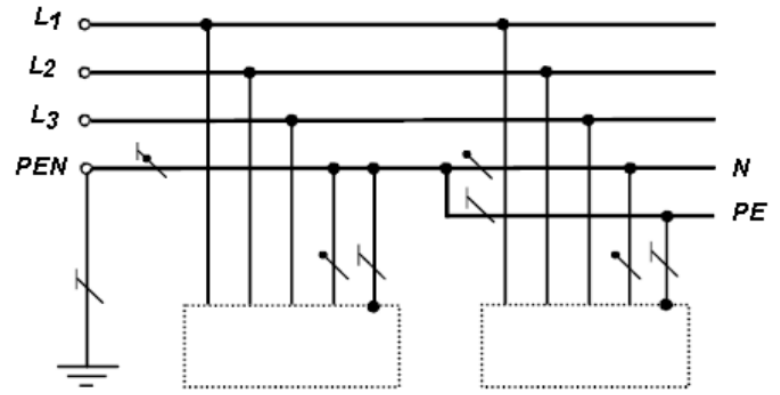

Figura 4. Esquema TN-C-S (RTIEBT edição anotada)

\section{- $\quad$ Regime IT - neutro isolado}

Nesta configuração, todas as partes ativas estão isoladas da terra ou um ponto destas está ligado à terra por meio de uma impedância, sendo as massas da instalação elétrica ligadas à terra.
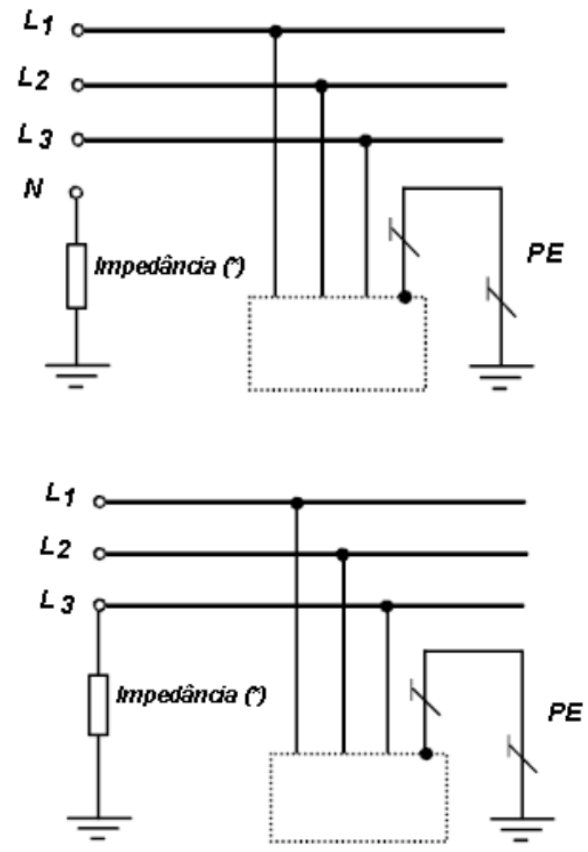

Figura 5. Esquema IT (RTIEBT edição anotada)

\section{Conceito de tensão de contacto}

A tensão de contacto é a tensão que aparece entre duas partes, simultaneamente acessíveis, em caso de defeito de isolamento de potenciais diferentes (234.2 RTIEBT).

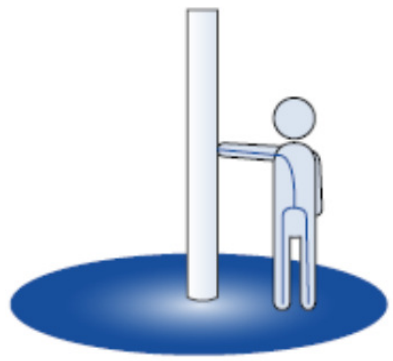

Figura 6. Tensão de contacto

Para garantirmos uma tensão de contacto máxima de $50 \mathrm{~V}$ ou $25 \mathrm{~V}$ se existirem massas empunháveis devemos avaliar a resistência de terra da malha de defeito cujo teste consiste no seguinte:

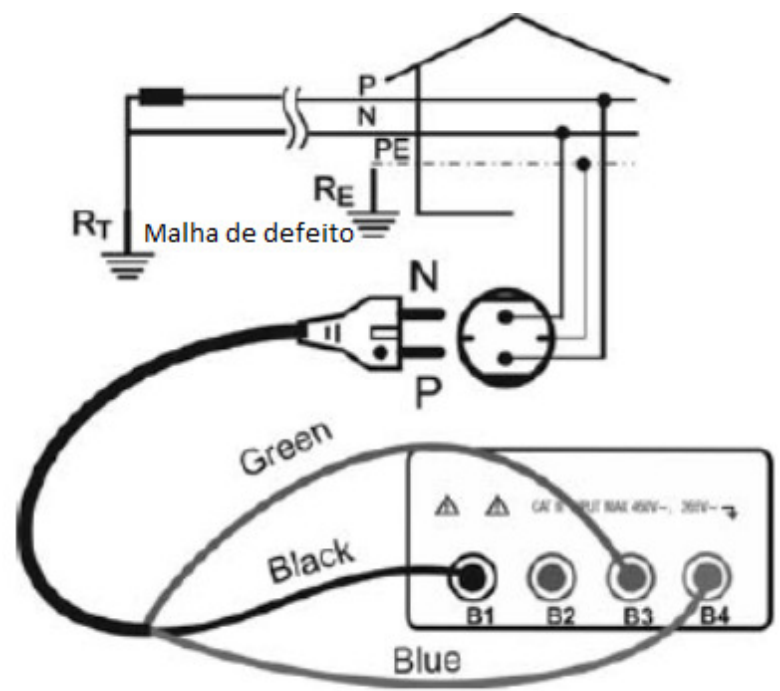

Figura 7. Medição da resistência da malha de defeito

(Manual HT sirius 87)

Vamos injetar $15 \mathrm{~mA}$ na fase que vai fechar através do terra de serviço pelo terra de proteção (na própria tomada) cujo valor não deverá exceder o que consta na tabela 5 . 
Tabela 5. valor máximo da resistência do elétrodo de terra das massas em função da sensibilidade do dispositivo diferencial

\begin{tabular}{|c|c|c|c|}
\hline \multicolumn{2}{|c|}{ 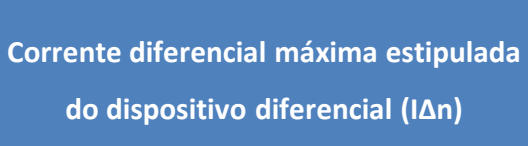 } & $\begin{array}{l}\text { Valor máximo da resistência do } \\
\text { elétrodo de terra das massas }\end{array}$ & $\begin{array}{l}\text { Valor máximo da resistência } \\
\text { do elétrodo de terra das }\end{array}$ \\
\hline \multirow{5}{*}{ Baixa Sensibilidade } & $20 \mathrm{~A}$ & 2,5 & 1,23 \\
\hline & $10 \mathrm{~A}$ & 5 & 2,5 \\
\hline & $5 \mathrm{~A}$ & 10 & 5 \\
\hline & $3 A$ & 17 & 8,3 \\
\hline & $1 \mathrm{~A}$ & 50 & 25 \\
\hline \multirow{3}{*}{ Média Sensibilidade } & $500 \mathrm{~mA}$ & 100 & 50 \\
\hline & $300 \mathrm{~mA}$ & 167 & 83,3 \\
\hline & $100 \mathrm{~mA}$ & 500 & 250 \\
\hline \multirow{3}{*}{ Alta Sensibilidade } & $30 \mathrm{~mA}$ & 1665 & 833,3 \\
\hline & $12 \mathrm{~mA}$ & 4170 & 2083 \\
\hline & $6 \mathrm{~mA}$ & 8330 & 4167 \\
\hline \multicolumn{4}{|c|}{ Tensão limite de contacto UL } \\
\hline
\end{tabular}

A tabela é construída com base na seguinte expressão:

$$
\mathrm{F} \leq \frac{\mathrm{U}}{\mathrm{It}}
$$

Onde:

R - Resistência de terra

Uc - Tensão de contacto

It - Corrente que garante o funcionamento automático. do dispositivo de proteção

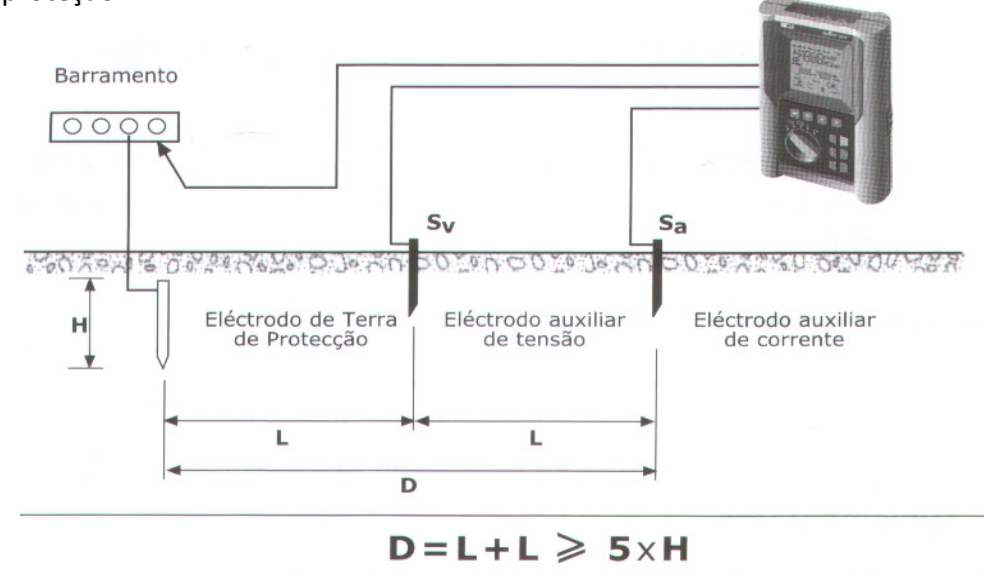

Figura 8. Medição da resistência de terra pelo método volt - amperimétrico ou 3P (Manual HT sirius 87)
A figura 8 mostra o esquema de medição da resistência de terra pelo método volt - amperimétrico ou 3P. 


\subsection{Método com recurso a pinças de medição de terra}

Como vantagens:

- $\quad$ Facilidade de medir

- Não necessita de desligar os pontos de medida

Porém convém referir que este método nem sempre funciona, convém ver bem no manual de instruções a forma correta de utilização ou junto de um fornecedor credenciado.

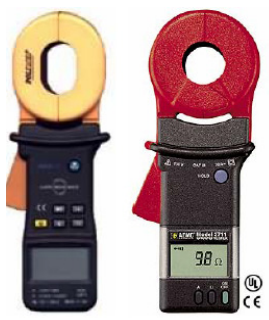

Figura 9. Medição da resistência de terra com recurso a pinças de medição de terra

\section{Medição da resistividade do terreno}

\section{- Método Wenner}

Por vezes procuramos obter uma boa terra e ao fim de muitas tentativas lá conseguimos. Porém o Método Wenner é um precioso auxiliar no que diz respeito á avaliação do solo onde vamos fazer a nossa terra. Assim vamos utilizar os quatro elétrodos, distanciando-os entre si considerando a distancia "a" igual a $1 \mathrm{~m}, 2 \mathrm{~m}, 3 \mathrm{~m}$ até $10 \mathrm{~m}$, como podemos ver na figura 10.

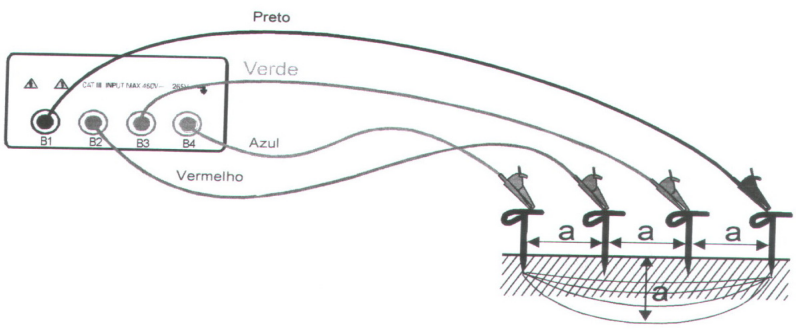

Figura 10. Medição da resistividade do terreno - Método de Wenner (Manual HT sirius 87)
As várias medidas de "a" estão associadas á profundidade pela expressão $h=3 /(4)$, podendo assim avaliar a estratificação do solo.

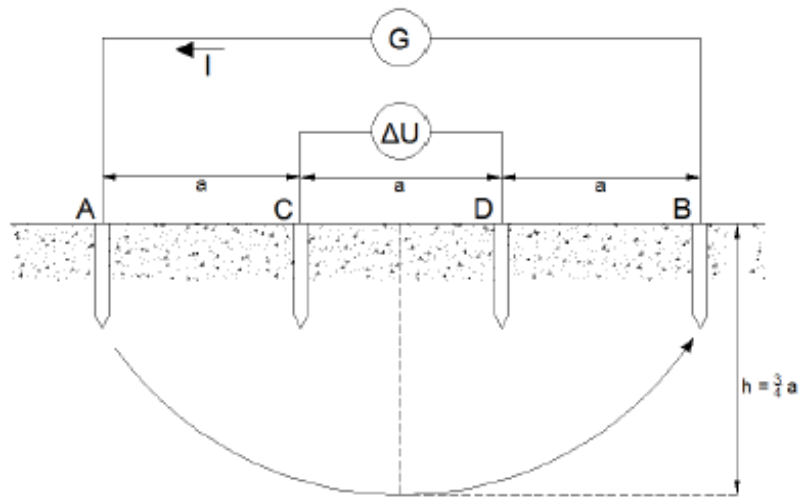

Figura 10a. Medição da resistividade do terreno - Método de Wenner (Manual HT sirius 87)

Em cada medida "a" referida anteriormente ( para 1m, 2m, etc.) registamos no eixo dos $x x$ e a resistividade do solo $\rho$ no eixo dos yy pela leitura no aparelho, podemos obter curvas seguintes:

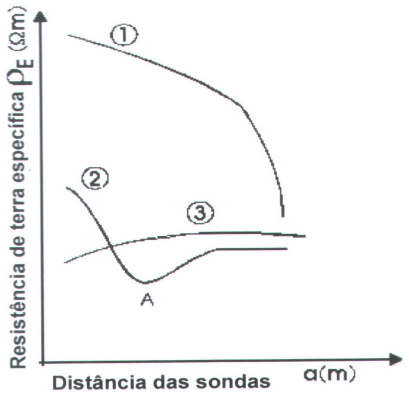

Figura 11. Curvas de resistividade do terreno (Manual HT sirius 87 )

Curva 1 - $\rho$ diminui com a profundidade. Obtemos bons resultados usando por exemplo um piquete em profundidade.

Curva 2 - $\rho$ diminui até á profundidade " $\mathrm{A}$ " pelo que não vale a pena aumentar a profundidade dos piquetes para alem de " $\mathrm{A}$ ".

Curva 3- $\rho$ neste caso não ganhamos muito com a profundidade. 
Neste contexto poderemos escolher a técnica mais adequada para instalação do nosso elétrodo de terra.

No caso de a medida suscitar duvidas ou poder ter sido influenciada por obstáculos existentes no subsolo, podemos fazer uma contra prova com uma outra medição ortogonal.

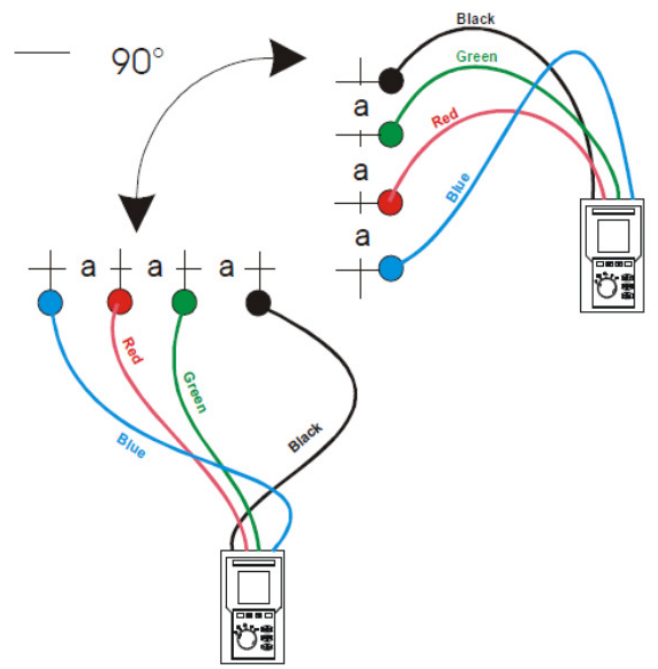

Figura 12. Medição da resistividade do terreno - Método de Wenner - Medição ortogonal (Manual HT sirius 87)

\section{Estimativa do valor da resistência de terra}

A título de exemplo a resistência de um piquete na vertical.

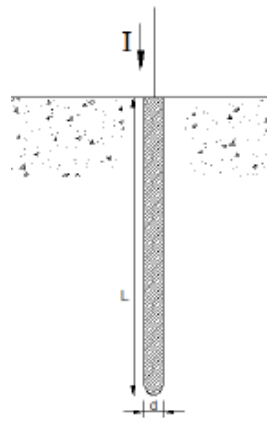

$$
R t=\frac{\rho}{L}
$$

A resistência de terra de um piquete na horizontal será:

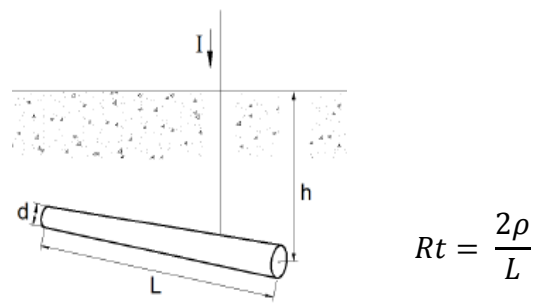

A resistência de um sistema de elementos em malha seria:

$$
R t=\frac{\rho}{4 r}
$$

Onde:

r Raio do circulo que circunscreve a malha.

\section{Como diminuir o valor da resistência de terra}

Se houver necessidade de diminuir o valor da resistência de terra podemos recorrer aos seguintes métodos:

- Aumenta o comprimento dos tubos ou varetas enterradas no solo;

- Aumentar a superfície das chapas ou das fitas em contacto com o solo;

- Enterrar no solo um número de elementos suficiente para que, uma vez ligados entre si, se possa atingir o valor desejado.

- Aumentar a profundidade a que o elétrodo de forma a atingir uma camada de terra mais húmida e melhor condutora;

- Aumentar a condutibilidade do solo, preparando-o convenientemente com adição de substâncias condutoras adequadas, como por exemplo o sulfato de cobre.

\section{Conclusão}

Conhecendo as propriedades do solo e os métodos aqui abordados poderemos então decidir de uma forma mais convicta sobre o nosso projeto de terra.

Com o Método Wenner, poderemos fazer uma aproximação dos valores de terra que procuramos, bem como a profundidade mais adequada, que nem em todos os casos funciona, quanto mais fundo melhor. Assim por vezes o recurso a elétrodos na vertical ou horizontal, dependerá do estudo de estratificação do solo. 